\title{
Study Protocol \\ Genomics of Gulf War Illness in U.S. Veterans Who Served during the 1990-1991 Persian Gulf War: Methods and Rationale for Veterans Affairs Cooperative Study \#2006
}

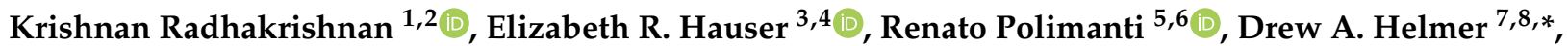 \\ Dawn Provenzale ${ }^{3,4}$, Rebecca B. McNeil ${ }^{3}$, Alysia Maffucci ${ }^{5}$, Rachel Quaden ${ }^{9}$, Hongyu Zhao ${ }^{5,10}$, \\ Stacey B. Whitbourne ${ }^{9,11,12}$, Kelly M. Harrington ${ }^{9,13} \mathbb{0}$, Jacqueline Vahey ${ }^{3,14}$, Joel Gelernter ${ }^{5,6}$, \\ Daniel F. Levey ${ }^{15,16}$, Grant D. Huang ${ }^{17}$, John Michael Gaziano ${ }^{9,11}$, John Concato ${ }^{6,18}$ and Mihaela Aslan ${ }^{5,6}$
}

check for

updates

Citation: Radhakrishnan, K.; Hauser, E.R.; Polimanti, R.; Helmer, D.A.; Provenzale, D.; McNeil, R.B.; Maffucci, A.; Quaden, R.; Zhao, H.; Whitbourne, S.B.; et al. Genomics of Gulf War Illness in U.S. Veterans Who Served during the 1990-1991 Persian Gulf War: Methods and Rationale for Veterans Affairs Cooperative Study \#2006. Brain Sci. 2021, 11, 845. https://doi.org/10.3390/ brainsci11070845

Academic Editor: Pierluigi Zoccolotti

Received: 29 March 2021

Accepted: 18 June 2021

Published: 25 June 2021

Publisher's Note: MDPI stays neutral with regard to jurisdictional claims in published maps and institutional affiliations.

Copyright: (c) 2021 by the authors. Licensee MDPI, Basel, Switzerland. This article is an open access article distributed under the terms and conditions of the Creative Commons Attribution (CC BY) license (https:/ / creativecommons.org/licenses/by/ $4.0 /)$.
1 Center for Behavioral Health Statistics and Quality, Substance Abuse and Mental Health Services Administration, Rockville, MD 20857, USA; kradhakrishnan05@gmail.com

2 College of Medicine, University of Kentucky, Lexington, KY 40536, USA

3 VA Cooperative Studies Program Epidemiology Center-Durham, Department of Veterans Affairs, Durham, NC 27705, USA; elizabeth.hauser@duke.edu (E.R.H.); dawn.provenzale@va.gov (D.P.); rmcneil@rti.org (R.B.M.); jacqueline.vahey@va.gov (J.V.)

4 Department of Biostatistics and Bioinformatics, Duke University, Durham, NC 27705, USA

5 Cooperative Studies Program Clinical Epidemiology Research Center (CSP-CERC), VA Connecticut Healthcare System, West Haven, CT 06516, USA; renato.polimanti@yale.edu (R.P.); alysia.maffuci@va.gov (A.M.); hongyu.zhao@yale.edu (H.Z.); joel.gelernter@yale.edu (J.G.); mihaela.aslan@va.gov (M.A.)

6 School of Medicine, Yale University, New Haven, CT 06511, USA; john.concato@yale.edu

7 Center for Innovations in Quality, Effectiveness, and Safety (IQuESt), Michael E. DeBakey VA Medical Center, Houston, TX 77030, USA

8 Department of Medicine, Baylor College of Medicine, Houston, TX 77030, USA

9 Massachusetts Veterans Epidemiology Research and Information Center (MAVERIC), VA Boston Healthcare System, Boston, MA 02130, USA; rachel.quaden@va.gov (R.Q.); stacey.whitbourne@va.gov (S.B.W.); kelly.harrington@va.gov (K.M.H.); michael.gaziano@va.gov (J.M.G.)

10 Department of Biostatistics, Yale School of Public Health, New Haven, CT 06520, USA

11 Department of Medicine, Harvard Medical School, Boston, MA 02115, USA

12 Department of Medicine, Division of Aging, Brigham and Women's Hospital, Boston, MA 02115, USA

13 Department of Psychiatry, Boston University School of Medicine, Boston, MA 02118, USA

14 Computational Biology and Bioinformatics Program, Duke University, Durham, NC 27705, USA

15 Division of Human Genetics, Department of Psychiatry, School of Medicine, Yale University, New Haven, CT 06511, USA; daniel.levey@yale.edu

16 Department of Psychiatry, Veterans Affairs Connecticut Healthcare Center, West Haven, CT 06516, USA

17 Cooperative Studies Program, VA Office of Research and Development, Washington, DC 20420, USA; grant.huang@va.gov

18 Food and Drug Administration, Silver Spring, MD 20993, USA

* Correspondence: Drew.helmer@va.gov

Abstract: Background: Approximately 697,000 members of the U.S. Armed Forces were deployed to the Persian Gulf in support of the 1990-1991 Persian Gulf War (GW). Subsequently, many deployed and some non-deployed veterans developed a chronic multi-symptom illness, now named Gulf War Illness (GWI). This manuscript outlines the methods and rationale for studying the genomics of GWI within the Million Veteran Program (MVP), a VA-based national research program that has linked medical records, surveys, and genomic data, enabling genome-wide association studies (GWASs). Methods: MVP participants who served in the military during the GW era were contacted by mail and invited to participate in the GWI study. A structured health questionnaire, based on a previously tested instrument, was also included in the mailing. Data on deployment locations and exposures, symptoms associated with GWI, clinical diagnoses, personal habits, and health care utilization were collected. Self-reported data will be augmented with chart reviews and structured international classification of disease codes, to classify participants by GWI case status. We will develop a phenotyping algorithm, based on two commonly used case definitions, to determine GWI status, and then conduct a nested case-control GWAS. Genetic variants associated with GWI will be 
investigated, and gene-gene and gene-environment interactions studied. The genetic overlap of GWI with, and causative mechanisms linking this illness to, other health conditions and the effects of genomic regulatory mechanisms on GWI risk will also be explored. Conclusions: The proposed initial GWAS described in this report will investigate the genomic underpinnings of GWI with a large sample size and state-of-the-art genomic analyses and phenotyping. The data generated will provide a rich and expansive foundation on which to build additional analyses.

Keywords: Persian Gulf War deployment status; Gulf War Illness; phenotyping; genomics; exposures; U.S. veteran

\section{Introduction}

In response to Iraq's invasion of Kuwait on 2 August 1990, a multinational coalition force was created to liberate Kuwait [1]. Approximately 697,000 members of the U.S. Armed Forces, mainly men (approximately 7\% women [2]), were deployed in support of the 1990-1991 Persian Gulf War [1,3,4]. Although the duration of deployment was brief, and rates of injury and disease were low compared to other wars, a substantial fraction of veterans reported a chronic multi-symptom illness in temporal association with deployment $[1,5,6]$. For example, in an army base in Indiana, 125 Gulf War veterans presented in early 1992 with various symptoms. The most common symptom was fatigue, reported by $71 \%$ of the 79 soldiers who were subsequently evaluated by a multidisciplinary team [7]. Other symptoms endorsed by a majority of the 79 included sleep disturbance $(57 \%)$, forgetfulness $(54 \%)$, and joint pain $(54 \%)$. Despite thorough medical and psychiatric evaluations and numerous screening tests, no unifying diagnosis could be made, and the symptoms were attributed to stress [7].

Deployment to the Persian Gulf was inherently stressful, and military personnel were also exposed to agents of potential concern, identified over the ensuing years, such as pyridostigmine bromide, infections, pesticides, solvents, depleted uranium, and air pollutants from burning trash and oil well fires $[1,3,4,6,8]$. In addition, both deployed and non-deployed veterans received multiple vaccinations in a short time frame. It has been suggested that some of these exposures could be related to risk for Gulf War Illness, based on self-reports, but this hypothesis is not supported when vaccination data based on medical records are considered [9]. In response to concerns regarding illness attributed by veterans to Gulf War service, various clinical and research programs were initiated by the Department of Defense and the Department of Veterans Affairs, and a workshop was held in April 1994 specifically to explore the evidence for increased incidence of unexpected illnesses attributable to deployment to the Persian Gulf [10]. The general conclusion was that exposure to the Persian Gulf theater of operations had produced adverse health effects, but no single disease or syndrome was apparent, and further research was necessary to better characterize this condition $[1,3,8,10,11]$.

Numerous clinical and epidemiologic studies have since been undertaken in various coalition nations to understand the etiology, pathophysiology, and prognosis of what is now called Gulf War Illness (GWI) [12-14], and to develop a reliable and clinically useful case definition [8,14-22]. GWI remains a symptom-based illness, as defined by two generally accepted research case definitions, referred to as CDC [23] and Kansas [24]. Both definitions are based on self-reported chronic symptoms ( $>6$ months in duration): in the CDC classification involving any two of three domains (fatigue, musculoskeletal pain, cognitive/mood) [23]; and in the Kansas definition involving any three of six domains (fatigue, musculoskeletal pain, cognitive/neuro/mood, pulmonary, gastrointestinal, skin) [24]. In addition, the latter definition considers exclusionary criteria (e.g., serious mental illness, multiple sclerosis, diabetes) that might explain the symptom complex in an individual [24]. Despite more than $\$ 300$ million being invested by federal agencies in GWI research since 1992 [25-28], the causative agent(s) and the underlying pathophysiology 
of GWI remain elusive, as have effective treatments [14]. It is clear, however, that this condition affects a large fraction of deployed, and a smaller fraction of non-deployed, military personnel $[8,14,15,22-24,29-49]$.

Given the complex heterogeneous nature of GWI and the long latency period in some veterans but not in others, genetic and epigenetic studies have the potential to improve understanding of this condition and possibly identify biologic mechanisms of disease $[8,14,16]$. Interactions between genetic and environmental factors, such as exposure to toxic chemicals, may play a role in the underlying pathophysiology $[14,17,22]$. For example, genetic variants of the xenobiotic metabolizing enzymes paraoxonases (PON) and butyrylcholinesterase (BChE) have been examined in a number of studies involving Gulf War era veterans, and inferences made concerning their associations with GWI [12,14,17,22,50]. However, based on a critical analysis of several genetic studies, the Institute of Medicine (IOM) concluded that these studies were underpowered and inconsistent $[12,14]$. Large-scale genome-wide studies are needed to dissect the polygenic architecture of complex diseases and traits [51], including multi-factorial disorders such as GWI.

To expand the scope of ongoing epidemiologic and biomarker research on GWI, the Department of Veterans Affairs (VA) initiated the VA Cooperative Studies Program (CSP) \#2006, "Genomics of Gulf War Illness in Veterans", to conduct a case-control, genomewide association study (GWAS) in a large cohort of Gulf War era veterans. CSP \#2006 is linked to the VA Million Veteran Program (MVP), a VA-based infrastructure resource for conducting genomic research [52]. Designed to facilitate the study of how genes affect health, MVP is developing a large database of genotypes and health information from the VA's electronic health record (EHR) system and surveys collected from Veterans Health Administration (VHA) enrollees. The VA has a long-established history of successfully using EHR systems in research [53], thus providing us with an unparalleled opportunity to link participants' genetic data to clinical outcomes. MVP enrollees include veterans who served in the military during the Persian Gulf War, and CSP \#2006 will analyze data from MVP for this subgroup.

The primary objective of CSP \#2006 is to identify genetic variants associated with GWI. A secondary objective is to examine interactions between genetic variants and self-reported Gulf War environmental exposures on risk of developing GWI. We will also examine (i) the genetic overlap of GWI with other physical and mental disorders, (ii) potential causative mechanisms that may link GWI to other health conditions, and (iii) effects of genomic regulatory mechanisms across tissues and cell types on GWI risk. These investigations will provide an unprecedented opportunity to classify and understand GWI. In this paper, we report on several aspects of CSP \#2006, focusing on the initial planned genomic analyses.

\section{Methods}

\subsection{Overview}

The primary analysis of CSP \#2006, and the focus of this report, is a GWAS of GWI. We will conduct a case-control study nested within the cohort of 1990-1991 Persian Gulf War era veterans in the MVP sample. We will select cases with GWI and controls without GWI from the genotyped MVP participants who served during this war, irrespective of deployment status. The preliminary designation of GWI cases will be based on two commonly used definitions, both endorsed by the IOM [13] (as described below). The pool of potential GWI cases will be identified using a phenotyping algorithm that primarily evaluates self-reported information from a questionnaire mailed to participants. Case status from self-reported data will be corroborated with VA's EHR information, with the latter source of data reviewed for a formal GWI diagnosis or requisite evidence of appropriate signs and symptoms and chronic health conditions. Control participants will not have evidence of GWI based on self-reported survey responses. An initial pilot study of 600 Gulf War era veterans assessed feasibility of identifying and developing phenotypic data prior to initiating the fully powered study. 


\subsection{Case Definition}

In a 2014 report of ongoing multisymptom illness among veterans of the Persian Gulf War, the IOM acknowledged the lack of a "gold standard" case definition for this illness [13]. Nonetheless, the report recognized that the CDC [23] and Kansas [24] definitions of GWI include the symptoms most often reported by veterans, and recommended use of these two definitions in VA research [13]. These define the GWI phenotypes to be used in the primary GWAS and $\mathrm{G} \times \mathrm{E}$ analyses described here.

\subsubsection{CDC Definition}

Fukuda et al. [23] defined cases on the basis of self-reported symptoms and duration ( $<6$ months or $\geq 6$ months) and intensity (mild, moderate or severe) of each symptom present. Participants completed a questionnaire, which asked about 35 symptoms that had been identified during an earlier exploratory study. Following both a clinical and a statistical approach, a case was defined as a participant endorsing one or more symptoms, of at least six months duration, from two or more of the following three categories: fatigue; mood and cognition (symptoms of feeling depressed, difficulty remembering or concentrating, feeling moody, feeling anxious, trouble finding words, and difficulty sleeping); and musculoskeletal (symptoms of joint pain, joint stiffness, and muscle pain). Moreover, a case was classified as severe if each case-defining symptom was rated as severe; otherwise, the case was called mild-moderate.

The CDC definition captures the three symptoms commonly reported in the literature but is broad and inclusive (especially the mild-moderate form), resulting in a high prevalence rate [22]. In practice, it has been found to be useful in clinical settings to rule out disease [42]. This definition has been the most commonly used and is accepted internationally $[15,22]$. The IOM has recommended its use in clinical practice $[13,14]$.

\subsubsection{Kansas Definition}

Steele [24] based the criteria for defining GWI on chronic fatigue syndrome, another disease defined primarily by symptoms. Symptom groups were defined based on measures of correlation and comparisons between the deployed and the non-deployed. Participants were asked about 37 symptoms in six domains: fatigue and sleep; pain; neurologic, cognitive and mood; gastrointestinal; respiratory; and skin. For each symptom present, the duration and severity were also measured. Steele [24] also identified exclusionary conditions, including medical and psychiatric diagnoses that were not different in the deployed and non-deployed veterans, but might confound the diagnosis of GWI. Specifically, any of the following diagnoses was a reason for exclusion from consideration as a case: cancer; diabetes; heart disease; chronic infectious disease; problems resulting from postwar injuries; liver disease; lupus; multiple sclerosis; stroke; or any serous psychiatric condition, such as psychosis, bipolar disorder, or one requiring hospitalization since 1991 [32]. A case was defined as a respondent with at least one moderately severe symptom or two or more symptoms, within at least three of the six domains, and no exclusionary condition.

Overall, the Kansas definition is more restrictive than the CDC criteria and therefore identifies GWI at lower prevalence rates [22]. However, because the Kansas definition excludes veterans with common chronic diseases, it can potentially exclude GWI cases if the "comorbidities" are actually part of a Gulf-War-related ailment or they developed after onset of GWI, as part of the aging process.

The Kansas [24] and CDC [23] case definitions of Gulf War Illness are illustrated schematically in Figure 1. Symptom domains and constituent individual symptoms are specified for the two case definitions, as well as the exclusionary criteria utilized in the Kansas case definition [54]. 

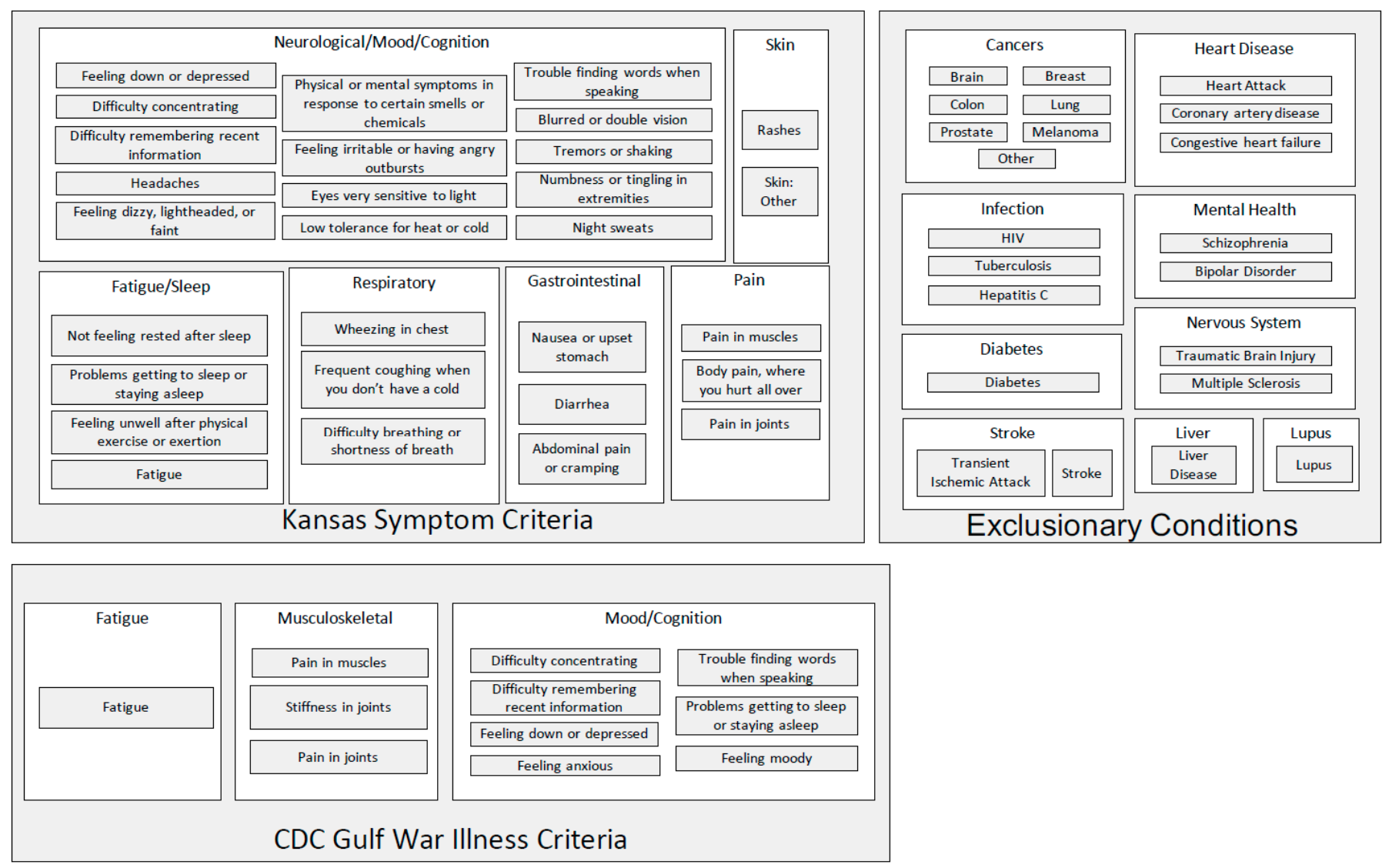

Figure 1. The Kansas [24] and CDC [23] case definitions of Gulf War Illness.

\subsection{Population/Sample/Recruitment}

The CSP \#2006 target population is the set of veterans who served in the military during the 1990-1991 Persian Gulf War era and represents a subset of MVP participants. As described elsewhere [52], the MVP sample, representing over 1 million veterans enrolled in the VHA, consists of a diverse mix of former US military service members of varying age, race/ethnicity, sex, military experience, and geographical location. As of 21 October 2020, $5,918,395$ veteran users of the VHA have been invited by mail to participate in the MVP, 829,975 have enrolled, 518,610 (62.5\%) have completed the baseline MVP questionnaire, 390,807 (47.1\%) have completed the lifestyle survey, 351,218 (42.3\%) have completed both, and 455,789 (55.0\%) genotypes are available for analysis. MVP participants volunteer to participate, and are generally representative of VHA users, but differ somewhat with respect to demographic, military, and health characteristics from the population of living veterans [55].

The potential study population for CSP \#2006 was identified by matching data from the Department of Defense Manpower Data Center (DMDC) with a list of MVP participants who self-reported service during the 1990-1991 Persian Gulf War era (August 1990-July 1991). Permission to use these databases was obtained in accordance with VA policies. Waivers of HIPAA authorization and informed consent were approved to generate contact information for potential study participants.

These veterans were contacted by mail and invited to participate in CSP \#2006. The invitation letter was followed by a 20-page, optical-scan formatted, structured health questionnaire mailed to MVP participants who did not opt-out of the study after initial contact. The survey instrument was designed to be consistent with other GWI questionnaires used within the VA [56], which have collected service details including deployment locations and exposures, health information in the form of symptoms associated with GWI, diag- 
noses of specific medical and psychiatric illnesses, personal habits, and health care and hospitalization utilization.

\subsection{Chart Reviews}

To assess self-reported symptoms and disease diagnoses, and to validate case-control classification, we are conducting chart reviews for symptoms, exposures, and diagnoses recorded by clinicians in the clinical and disability examination notes. Explicit chart review rules will allow for trained reviewers to abstract relevant details from a small subset of participants. These data will be used to corroborate self-reported survey responses. Structured data, including international classification of disease (ICD) codes, will also be utilized in exploring GWI phenotypes and classifying participants by GWI case status, particularly with regard to exclusionary conditions for the Kansas case definition.

\subsection{Phenotyping}

GWI case status for the primary genomic analyses will be assigned based on selfreported responses to survey items related to symptoms and medical conditions (see appendix for survey instrument) consistent with the CDC and Kansas case definitions described above. Symptoms will be considered if onset was during or after deployment and present for more than 6 months. Symptom severity will be incorporated and allow for differentiation between CDC mild-moderate and CDC severe phenotypes. We will also explore differences between GWI defined by the Kansas case definition with the exclusionary conditions and without consideration of the exclusionary conditions.

Exposures will be derived from several survey items asking about deployment status, location in theater, and specific exposures of interest. In conjunction with self-reported branch of service, classification of exposure status will be corroborated through exploration of the self-reported responses to these items. Ambiguous or implausible patterns of response to exposure and location items will be adjudicated using rule-based algorithms derived from the published literature and input from the research team and CSP \#2006 executive committee.

\subsection{Genotyping}

The collection, shipping, and storage of biospecimens, as well as specifics of the MVP genotyping microarray, have been described previously [52]. Blood samples collected from consented participants are mailed to the VA Central Biorepository in Boston, which ships them to one of two approved vendors, BioStorage Technologies, Inc., Indianapolis, IN and AKESOgen, Norcross, GA, for genotyping using a custom Affymetrix $723 \mathrm{~K}$ chip ${ }^{\circledR}$. Development of the genetic database, quality control measures, and imputation have been described [57] and are maintained by the VA's Genomic Information System for Integrated Science (GenISIS). The current dataset includes information regarding high quality genotypes for 668,418 common and rare variants assessed in 459,777 MVP participants [57].

\subsection{Power Calculation for Genetic Analysis}

Among the veterans enrolled in MVP, 109,976 served during the 1990-1991 Persian Gulf War Era, all of whom were mailed the GW survey, and 45,044 surveys were returned. Based on these numbers and estimates of case status in similar cohorts, we expect to obtain information regarding GWI status in approximately 14,700 cases and 27,300 controls. Additional participants may be included, based on information derived from the electronic health records of all Gulf War era veterans enrolled in the MVP. Considering common alleles (effect allele frequency, EAF > 5\%) with moderate effects (odds ratio, OR > 1.05), our case-control trans-ancestry meta-analysis has $80 \%$ statistical power to detect OR $=1.1$ (95\% confidence interval: $1.06-1.14)$ for EAF $>35 \%$. However, we are underpowered to detect small genetic associations (OR $\leq 1.05,<80 \%$ statistical power). With respect to the gene-environment interaction analysis, we will conduct a multivariate gene-environment interaction analysis using the structLMM method (see description in 
the Data Analysis section). As previously reported [58], this approach is more powerful than a single environment, one degree of freedom fixed-effect test. The investigation of multivariate gene-environment interactions has several power advantages, including the ability to (i) identify interactions that are simultaneously driven by multiple environments; (ii) assess unobserved drivers of gene-environment interactions using combinations of multiple environmental variables as proxy; and (iii) reduce multiple testing burden due to the joint test design.

\subsection{Data Analysis}

Association and interaction analyses will be conducted using the MVP genome-wide data generated through a unified genetic quality control (QC) [57]. These genotype data were used to perform imputation with minimac3 [59], leveraging the 1000 Genomes Project reference panel [60]. For post-imputation QC, SNPs with imputation INFO scores of $<0.6$ or minor allele frequencies $(\mathrm{MAF})<0.01$ will be removed from the analysis.

The MVP cohort reflects the ancestry and ethnic diversity of the US population. MVP participants reported a wide range of ancestry and ethnic backgrounds, including Hispanic European/European American, African American/Afro-Caribbean, East Asian, and others. With nearly $30 \%$ of the participants being of non-European descent, MVP is the most diverse among large biobanks [57]. To model MVP genetic diversity appropriately in our analyses, we will use a recently developed supervised learning algorithm, HARE (harmonized ancestry and race/ethnicity) [61], to define a categorical stratification variable. Leveraging HARE, we will partition the MVP multi-ethnic cohort into non-overlapping strata. Within each HARE stratum, we will use principal components (PCs) to account for the variation in admixture proportions and/or geographic cline.

Association tests will be conducted using regression models implemented in PLINK 2.0 [62] and linear mixed models implemented in BOLT-LMM [63], to investigate the four GWI-relevant case-control phenotypes (CDC, CDC-severe, Kansas symptoms and Kansas symptoms and exclusions). With respect to our primary analysis, for each SNP we will model an additive genetic effect using the standard genome-wide significance level $(\alpha)$ of $5 \times 10^{-8}$. Ancestry and SNP-specific GWAS results will be databased for analysis of genetic correlation and for additional studies described below. For secondary analyses focused on multiple phenotypic outcomes, we will apply a false discovery rate correction. The association analysis will be performed in each HARE stratum, including sex, age, agesquared, and the top 10 PCs as covariates. The results generated from the HARE strata will be combined using a fixed-effects, inverse-variance weighted meta-analysis. Heterogeneity of genetic effects across strata will be evaluated in the meta-analysis. Additionally, we will also perform a cross-ancestry fine-mapping analysis to identify ancestry-specific effects.

Interaction analyses will be conducted using the recently developed StructLMM, a linear mixed-model approach to identify and characterize efficiently loci that interact with one or more environments [58]. These studies will permit us to simultaneously test the effect of multiple GWI risk factors, such as cumulative deployment time, deployment location, and self-reported exposures to pesticides, nerve gas, and pyridostigmine bromide. The StructLMM framework will identify loci with significant GWI-related interaction effects, along with evidence of heterogeneous effect sizes due to multivariate gene-environment interactions. For the loci identified, we will estimate the fraction of genetic variance explained by multivariate gene-environment interactions, and use Bayes factors (BF) between the full model and reduced models (i.e., with environmental variables removed) to identify GWI risk factors that are most relevant for the observed interactions. Similar to the association analyses described above, interaction tests will be conducted separately in each HARE stratum, including sex, age, age-squared, and the top 10 PCs as covariates, followed by meta-analysis of the stratum-specific results.

The genome-wide data generated by the association and interaction tests will provide the basis for a wide range of additional approaches, taking two general forms: (1) functional characterization of the underlying genetic architecture of GWI; and (2) categorization of the 
complex GWI phenotype with respect to the genetic contributions from related conditions. These analyses will require reference to external databases, such as GTEx (Genotype-Tissue Expression) that catalogs the tissue-specific regulatory potential of individual SNPs, as well as databases of additional omics features (i.e., transcriptome, epigenome, proteome, and microbiome) measured in relevant tissues, as well as comparisons to the phenotypic spectrum of loci identified in the association and interaction tests, through phenomewide association studies (PheWAS) [64] of the MVP cohort after excluding the Persian Gulf War era veterans, UK Biobank, [65] FinnGen (FinnGen. Available online: https: / / www.finngen.fi/ en (accessed on 21 June 2021)) [66], and other large biobanks.

To investigate the polygenicity of GWI, we will leverage established methods to model the independent associations expected across the human genome. Specifically, we will quantify the fraction of GWI phenotypic variance explained by additive effects of the variants, by using the linkage disequilibrium (LD) score regression method [67], and we will apply cross-phenotype LD score regression [68] to quantify the genetic liability of GWI that is shared (i.e., genetic correlation) with other human traits, including physical and mental disorders, biomarkers, and other relevant phenotypes. We will partition the heritability [69] across a broad set of functional annotations (e.g., cell type-specific elements) to identify the most relevant mechanisms involved in GWI pathogenesis. We will use the PrediXcan approach [70] and GTEx (Genotype-Tissue Expression) data [71] as a reference panel, to impute tissue-specific transcriptomic profiles in GWI cases and controls. The goal of these analyses is to develop risk-prediction models of genetic and genomic predictors (polygenic risk scores), combined with trans-ethnic analysis and phenotypic characterization that can be used to perform genomic structural equation modeling (SEM) [72] and Mendelian randomization (MR) [73]. These analyses at the intersection of the genomic and phenotypic complexities of GWI will enable examination of the robustness of findings and validation of analyses, as well as investigation of the mediation processes among GWI-related risk factors $[74,75]$.

\section{Discussion}

The VA Cooperative Studies Program (CSP) \#2006, "Genomics of Gulf War Illness", represents a major milestone in the study of GWI, with the largest dataset to date of genomic and phenotypic information about veterans with GWI and veterans without GWI who served in the US military contemporaneously. The GWAS study design outlined in this paper and the primary analysis of CSP \#2006 will potentially produce important findings about genetic variation associated with GWI, potential pathophysiologic underpinnings of GWI, pleiotropy with other traits, and gene $\times$ environment interactions. The methods address the challenge of conducting genomic analyses on a symptom-based condition, in the absence of a recognized diagnostic biomarker.

This project is high priority to address the concerns of Gulf War veterans and veterans of other cohorts who attribute unexplained chronic symptoms or difficult-to-diagnose illness to recalled occupational and environmental exposures. This effort represents a significant leveraging of VA research infrastructure at a scale that GWI research has not experienced to date. It holds promise for a more in-depth look at factors not previously available to scientists and clinicians and provides avenues for scientific inquiry that bypass or overcome previous challenges in understanding GWI pathophysiology.

This report focuses on the initial GWAS analysis of CSP \#2006 and as work progresses the approaches employed to address the challenges of characterizing the GWI phenotype and the endophenotypes may be of more generalized relevance and applicability. There are several other chronic symptom-based conditions related to GWI, also with poorly understood pathophysiology and inadequate biomarkers of disease, such as chronic fatigue syndrome, fibromyalgia, and functional gastrointestinal disorders. Similarly, mental health conditions are mostly defined by symptoms and behaviors. The proposed study will provide an opportunity to place GWI symptoms in the context of related physical 
or psychiatric illnesses. Our approach to phenotyping GWI in CSP \#2006 may prove transferable to other conditions and other populations with complex symptoms.

Strengths of this project include the large sample size and the richness of the selfreported data from the surveys, especially the symptom and exposure reporting. In addition, the potential for incorporating structured and free text data from the EHR is promising and will be examined in the later stages of this project. Finally, the depth and breadth of experience among the study team provides high quality technical and analytical expertise for the project.

Weaknesses of this project include the reliance on self-reported data, limitations of the two case definitions to be used in primary analyses, and a dearth of objectively determined exposure data. These challenges, not unique to this study, are inherent in current stateof-the-art GWI research. Misclassification of GWI status is a major concern and multiple sources could contribute to this problem. We will initially rely on self-reported symptoms and health conditions to determine GWI status; symptoms are subjective by nature and self-report introduces the possibility of inaccuracies, recall bias and memory problems in this aging cohort. Corroboration of self-reported responses with documentation in the medical record will provide insights into the risk of misclassification.

The association between greater age and the chronic conditions included in the original Kansas definition is of distinct concern in this aging cohort. These comorbid conditions, which likely developed after the onset of GWI in those with GWI, may result in misclassification of GWI in our sample. We have some ability to explore symptom "year of onset" and "year first told" of a diagnosis to examine the temporal relationship, although the details of these analyses will need to be developed. We will also explore variants of the recommended case definitions of GWI to assess the consistency of meaningful genomic information across phenotypes and explore possible misclassification. For example, future analyses of CSP \#2006 data will explore different approaches to identifying exclusionary conditions for the Kansas GWI case definition. Another limitation of the study is the voluntary nature of participation in both MVP and CSP \#2006. This self-selection bias may reduce the genetic and phenotypic variability among participants, and limit potential for discovery of genetic associations of GWI. Similarly, survival bias is a limitation that cannot be addressed with this study.

There have been very few genomic studies of GWI [28], and none as large as the one proposed for this project. In fact, with fewer than 700,000 surviving deployed Gulf War veterans, our conservatively estimated sample ( $50 \%$ of 45,000 survey respondents deployed to GW) represents approximately $3 \%$ of the total population of exposed individuals. Because data generated by CSP \#2006 will be returned to the Million Veteran Program, findings from this study, including genotypes, will become available to future researchers, to expand upon and apply new approaches and methods as they become available. Moreover, combining genetic information with other omics information when it becomes available will contribute to future multi-omics studies of GWI. Data from multiple molecular layers may potentially allow for more accurate modeling of the complex dynamics driving GWI pathogenesis, as demonstrated in a recent analysis of potential COVID-19 treatment targets using the MVP [76].

In summary, CSP \#2006 represents a rigorous study of genomic underpinnings of GWI, based on sample size and state-of-the-art genomic analysis and phenotyping. The findings could well serve as a landmark study of this disease, and the data generated will provide a rich and expansive foundation upon which to build additional analyses.

Author Contributions: D.P., J.C., R.B.M., J.M.G., M.A., E.R.H., G.D.H. designed and wrote protocol. K.R., D.A.H., D.P., J.C., M.A. formulated and wrote manuscript. J.V., E.R.H. development of phenotyping algorithm. E.R.H., R.P., R.B.M., A.M., H.Z., J.V., D.F.L., G.D.H., J.M.G., R.Q., S.B.W., K.M.H., J.G. edited and contributed to the writing and organization of manuscript. All authors have consented to publication of this manuscript, which was also reviewed and approved for publication by the CSP executive and the MVP publications and presentations committees. All authors have read and agreed to the published version of the manuscript. 
Funding: This research was supported by VA Cooperative Studies Program study \#2006 and the Million Veteran Program. The contents represent the views of the authors and do not represent the views of the U.S. Department of Veterans Affairs, the Substance Abuse and Mental Health Services Administration, the U.S. Food and Drug Administration, the U.S. Department of Health and Human Services, or the United States Government.

Institutional Review Board Statement: The MVP program is conducted according to the guidelines of the Declaration of Helsinki and has full ethics approval by the VA Central Institutional Review Board (CIRB) and the Research and Development Committees (RDCs) of all participating recruitment, analysis, and coordinating sites.

Informed Consent Statement: Participants completed written informed consent prior to participation. CSP \#2006 study similarly has full ethics approval by the VA CIRB and RDCs of all participating analysis and coordinating sites. CSP \#2006 study is a secondary analysis of existing data from MVP (used in accordance with the original participant consent).

Data Availability Statement: Data and materials can be made available for review in accordance with VA CSP and MVP policy.

Acknowledgments: The authors would like to acknowledge the support of Timothy O'Leary, former Chief Research and Development Officer, Office of Research and Development, Veterans Health Administration; the team at the West Haven Cooperative Studies Program Epidemiology Center; MVP leadership, especially Suma Muralidhar; Victor Kalasinsky, former Gulf War Illness Program Director, Office of Research and Development, Veterans Health Administration; and Karen Block, Gulf War Illness Program Director, Office of Research and Development, Veterans Health Administration.

Conflicts of Interest: The authors declare no conflict of interest.

\section{References}

1. Institute of Medicine. Health Consequences of Service During the Persian Gulf War: Initial Findings and Recommendations for Immediate Action; The National Academies Press: Washington, DC, USA, 1995.

2. Institute of Medicine. Depleted Uranium, Sarin, Pyridostigmine Bromide, Vaccines. In Gulf War and Health; Fulco, C.E., Liverman, C.T., Sox, H.C., Eds.; The National Academies Press: Washington, DC, USA, 2000; Volume 1.

3. Institute of Medicine. Health Consequences of Service during the Persian Gulf War: Recommendations for Research and Information Systems; The National Academies Press: Washington, DC, USA, 1996.

4. Institute of Medicine. Gulf War and Health; The National Academies Press: Washington, DC, USA, 2016 ; Volume 10.

5. Institute of Medicine. Health Effects of Serving in the Gulf War. In Gulf War and Health; The National Academies Press: Washington, DC, USA, 2006; Volume 4.

6. RAC-GWVI (Research Advisory Committee on Gulf War Veterans' Illnesses). Gulf War Illness and the Health of Gulf War Veterans; US Government Printing Office: Washington, DC, USA, 2008.

7. DeFraites, R.F.; Wanat, E.R.; Norwood, A.E.; Williams, S.; Cowan, D.; Callahan, T. Investigation of a Suspected Outbreak of an Unknown Disease among Veterans of Operation Desert Shield/Storm, 123d Army Reserve Command, Fort Benjamin Harrison, Indiana, April, 1992; Report No.: WRAIR/TR-96-0002; Walter Reed Army Insitute of Research: Washington, DC, USA, 1992.

8. RAC-GWVI (Research Advisory Committee on Gulf War Veterans' Illnesses). Gulf War Illness and the Health of Gulf War Veterans: Research Update and Recommendations, 2009-2013. Available online: https:/ /www.va.gov/RAC-GWVI/RACReport2 014Final.pdf (accessed on 21 June 2021).

9. Mahan, C.M.; Kang, H.K.; Dalager, N.A.; Heller, J.M. Anthrax vaccination and self-reported symptoms, functional status, and medical conditions in the National Health Survey of Gulf War Era Veterans and Their Families. Ann. Epidemiol. 2004, 14, 81-88. [CrossRef]

10. The Persian Gulf experience and health. NIH Technology Assessment Workshop Panel. JAMA 1994, 272, 391-396. [CrossRef]

11. Gunby, P. Institute of Medicine calls for coordinated studies of Gulf War veterans' health complaints. JAMA 1995, 273, 444-445. [CrossRef]

12. Institute of Medicine. Update of Health Effects of Serving in the Gulf War. In Gulf War and Health; The National Academies Press: Washington, DC, USA, 2010; Volume 8.

13. Institute of Medicine. Chronic Multisymptom Illness in Gulf War Veterans: Case Definitions Reexamined; US Government Printing Office: Washington, DC, USA, 2014.

14. Institute of Medicine. Update of Health Effects of Serving in the Gulf War. In Gulf War and Health; Cory-Slechta, D., Wedge, R., Eds.; The National Academies Press: Washington, DC, USA, 2016; Volume 10.

15. Gwini, S.M.; Forbes, A.B.; Sim, M.R.; Kelsall, H.L. Multisymptom illness in Gulf War veterans: A systematic review and meta-analysis. J. Occup. Environ. Med. 2016, 58, 659-667. [CrossRef] [PubMed]

16. Heng, H.Q. Challenges and new strategies for Gulf War illness research. Environ. Dis. 2016, 1, 118. [CrossRef] 
17. Kerr, K.J. Gulf War illness: An overview of events, most prevalent health outcomes, exposures, and clues as to pathogenesis. Rev. Environ. Health 2015, 30, 273-286. [CrossRef]

18. Nettleman, M. Gulf War illness: Challenges persist. Trans. Am. Clin. Climatol. Assoc. 2015, 126, $237-247$.

19. Iversen, A.; Chalder, T.; Wessely, S. Gulf War illness: Lessons from medically unexplained symptoms. Clin. Psychol. Rev. 2007, 27, 842-854. [CrossRef]

20. Thomas, H.V.; Stimpson, N.J.; Weightman, A.L.; Dunstan, F.; Lewis, G. Systematic review of multi-symptom conditions in Gulf War veterans. Psychol. Med. 2006, 36, 735-747. [CrossRef] [PubMed]

21. Steele, L. Invited commentary: Unexplained health problems after Gulf War Service-Finding answers to complex questions. Am. J. Epidemiol. 2001, 154, 406-409. [CrossRef] [PubMed]

22. White, R.F.; Steele, L.; O'Callaghan, J.P.; Sullivan, K.; Binns, J.H.; Golomb, B.A.; Bloom, F.E.; Bunker, J.A.; Crawford, F.; Graves, J.C.; et al. Recent research on Gulf War illness and other health problems in veterans of the 1991 Gulf War: Effects of toxicant exposures during deployment. Cortex 2016, 74, 449-475. [CrossRef]

23. Fukuda, K.; Nisenbaum, R.; Stewart, G.; Thompson, W.W.; Robin, L.; Washko, R.M.; Noah, D.L.; Barrett, D.H.; Randall, B.; Herwaldt, B.L.; et al. Chronic multisymptom illness affecting air force veterans of the Gulf War. JAMA 1998, 280, 981-988. [CrossRef] [PubMed]

24. Steele, L. Prevalence and patterns of Gulf War illness in Kansas veterans: Association of Symptoms with Characteristics of Person, Place, and Time of Military Service. Am. J. Epidemiol. 2000, 152, 992-1002. [CrossRef] [PubMed]

25. Department of Veterans Affairs. Annual Summary. Federally Sponsored Research on Gulf War Veterans' Illnesses for 2016: US Department of Veterans Affairs. Available online: https: / /www.research.va.gov/pubs/docs/GulfWar2016-AnnualReport.pdf (accessed on 21 June 2021).

26. GAO Report to Congressional Requesters. Gulf War Illness: Improvements Needed for VA to Better Understand, Process, and Communicate Decisions on Claims: GAO Report to Congressional Requesters. 2017. Available online: https://www.gao.gov/ assets /690/685562.pdf (accessed on 21 June 2021).

27. CDMRP Department of Defense. Gulf War Illness Research Program. Strategic Plan: CDMRP Department of Defense. Available online: https: / / cdmrp.army.mil/gwirp/pdfs/GWIRP\%20Strategic\%20Plan.pdf (accessed on 21 June 2021).

28. US Department of Veterans Affairs. Gulf War Research Strategic Plan 2013-2017 (2015 Update): US Department of Veterans Affairs. Available online: http:/ / www.research.va.gov/pubs/docs/GWResearch-StrategicPlan.pdf (accessed on 21 June 2021).

29. Dursa, E.K.; Barth, S.K.; Schneiderman, A.I.; Bossarte, R.M. Physical and mental health status of Gulf War and Gulf Era veterans: Results from a large population-based epidemiological study. J. Occup. Environ. Med. 2016, 58, 41-46. [CrossRef] [PubMed]

30. Gwini, S.M.; Forbes, A.; Kelsall, H.; Ikin, J.F.; Sim, M.R. Increased symptom reporting persists in 1990-1991 Gulf War veterans 20 years post deployment. Am. J. Ind. Med. 2015, 58, 1246-1254. [CrossRef]

31. Smith, B.N.; Wang, J.M.; Vogt, D.; Vickers, K.; King, D.W.; King, L.A. Gulf war illness: Symptomatology among veterans 10 years after deployment. J. Occup. Environ. Med. 2013, 55, 104-110. [CrossRef]

32. Steele, L.; Sastre, A.; Gerkovich, M.M.; Cook, M.R. Complex factors in the etiology of Gulf War illness: Wartime exposures and risk factors in veteran subgroups. Environ. Health Perspect. 2012, 120, 112-118. [CrossRef]

33. Iannacchione, V.G.; Dever, J.A.; Bann, C.; Considine, K.A.; Creel, D.; Carson, C.P.; Best, H.; Haley, R.W. Validation of a research case definition of Gulf War illness in the 1991 US military population. Neuroepidemiology 2011, 37, 129-140. [CrossRef]

34. Li, B.; Mahan, C.M.; Kang, H.K.; Eisen, S.A.; Engel, C.C. Longitudinal health study of US 1991 Gulf War veterans: Changes in health status at 10-year follow-up. Am. J. Epidemiol. 2011, 174, 761-768. [CrossRef]

35. Kang, H.K.; Li, B.; Mahan, C.M.; Eisen, S.A.; Engel, C.C. Health of US veterans of 1991 Gulf War: A follow-up survey in 10 years. J. Occup. Environ. Med. 2009, 51, 401-410. [CrossRef]

36. Kelsall, H.L.; McKenzie, D.P.; Sim, M.R.; Leder, K.; Forbes, A.B.; Dwyer, T. Physical, psychological, and functional comorbidities of multisymptom illness in Australian male veterans of the 1991 Gulf War. Am. J. Epidemiol. 2009, 170, 1048-1056. [CrossRef]

37. King, L.A.; King, D.W.; Bolton, E.E.; Knight, J.A.; Vogt, D.S. Risk factors for mental, physical, and functional health in Gulf War veterans. J. Rehabil. Res. Dev. 2008, 45, 395-407. [CrossRef]

38. Blanchard, M.S.; Eisen, S.A.; Alpern, R.; Karlinsky, J.; Toomey, R.; Reda, D.J.; Murphy, F.M.; Jackson, L.W.; Kang, H.K. Chronic multisymptom illness complex in Gulf War I veterans 10 years later. Am. J. Epidemiol. 2006, 163, 66-75. [CrossRef]

39. Gray, G.C.; Reed, R.J.; Kaiser, K.S.; Smith, T.C.; Gastañaga, V.M. Self-reported symptoms and medical conditions among 11,868 Gulf War-era veterans: The Seabee health study. Am. J. Epidemiol. 2002, 155, 1033-1044. [CrossRef] [PubMed]

40. Unwin, C.; Hotopf, M.; Hull, L.; Ismail, K.; David, A.; Wessely, S. Women in the Persian Gulf: Lack of gender differences in long-term health effects of service in United Kingdom Armed Forces in the 1991 Persian Gulf War. Mil. Med. 2002, 167, 406-413. [CrossRef] [PubMed]

41. Wolfe, J.; Proctor, S.P.; Erickson, D.J.; Hu, H. Risk factors for multisymptom illness in US army veterans of the Gulf War. J. Occup. Environ. Med. 2002, 44, 271-281. [CrossRef] [PubMed]

42. Baker, D.G.; McQuarrie, I.G.; Murray, M.G.; Lund, L.M.; Dashevsky, B.A.; Mendenhall, C.L. Diagnostic status and treatment recommendations for Persian Gulf War veterans with multiple nonspecific symptoms. Mil. Med. 2001, 166, 972-981. [CrossRef]

43. Chalder, T.; Hotopf, M.; Unwin, C.; Hull, L.; Ismail, K.; David, A.; Wessely, S. Prevalence of Gulf war veterans who believe they have Gulf war syndrome: Questionnaire study. BMJ 2001, 323, 473-476. [CrossRef] 
44. Haley, R.W.; Luk, G.D.; Petty, F. Use of structural equation modeling to test the construct validity of a case definition of Gulf War syndrome: Invariance over developmental and validation samples, service branches and publicity. Psychiatry Res. 2001, 102, 175-200. [CrossRef]

45. Proctor, S.P.; Heaton, K.J.; White, R.F.; Wolfe, J. Chemical sensitivity and chronic fatigue in Gulf War veterans: A brief report. J. Occup. Environ. Med. 2001, 43, 259-264. [CrossRef]

46. Nisenbaum, R.; Barrett, D.H.; Reyes, M.; Reeves, W.C. Deployment stressors and a chronic multisymptom illness among Gulf War veterans. J. Nerv. Ment. Dis. 2000, 188, 259-266. [CrossRef]

47. Unwin, C.; Blatchley, N.; Coker, W.; Ferry, S.; Hotopf, M.; Hull, L.; Ismail, K.; Palmer, I.; David, A.; Wessely, S.C. Health of UK servicemen who served in Persian Gulf War. Lancet 1999, 16, 169-178. [CrossRef]

48. Haley, R.W.; Kurt, T.L.; Hom, J. Is there a Gulf War Syndrome? Searching for syndromes by factor analysis of symptoms. JAMA 1997, 277, 215-222. [CrossRef] [PubMed]

49. Zundel, C.G.; Krengel, M.H.; Heeren, T.; Yee, M.K.; Grasso, C.M.; Janulewicz Lloyd, P.A.; Coughlin, S.S.; Sullivan, K. Rates of chronic medical conditions in 1991 Gulf War veterans compared to the general population. Int. J. Environ. Res. Public Health 2019, 16, 949. [CrossRef] [PubMed]

50. Haines, D.D.; Ottenweller, J.E.; Dickens, B.F.; Mahmoud, F.F.; Levine, P.H. activity of paraoxonase/arylesterase and butyrylcholinesterase in peripheral blood of Gulf War era veterans with neurologic symptom complexes or post-traumatic stress disorder. J. Occup. Environ. Med. 2017, 59, 1000-1006. [CrossRef] [PubMed]

51. Pasaniuc, B.; Price, A.L. Dissecting the genetics of complex traits using summary association statistics. Nat. Rev. Genet. 2017, 18, 117-127. [CrossRef] [PubMed]

52. Gaziano, J.M.; Concato, J.; Brophy, M.; Fiore, L.; Pyarajan, S.; Breeling, J.; Whitbourne, S.; Deen, J.; Shannon, C.; Humphries, D.; et al. Million Veteran Program: A mega-biobank to study genetic influences on health and disease. J. Clin. Epidemiol. 2016, 70, 214-223. [CrossRef]

53. Brown, S.H.; Lincoln, M.J.; Groen, P.J.; Kolodner, R.M. VistA-U.S. Department of Veterans Affairs national-scale HIS. Int. J. Med. Inform. 2003, 69, 135-156. [CrossRef]

54. Gifford, E.J.; Vahey, J.; Hauser, E.R.; Sims, K.J.; Efird, J.T.; Dursa, E.K.; Steele, L.; Helmer, D.A.; Provenzale, D. Gulf War illness in the Gulf War era cohort and biorepository: The Kansas and Centers for Disease Control definitions. Life Sci. 2021, $278,119454$. [CrossRef]

55. Dursa, E.K.; Barth, S.K.; Bossarte, R.M.; Schneiderman, A.I. Demographic, military, and health characteristics of VA health care users and nonusers who served in or during operation enduring freedom or operation Iraqi Freedom, 2009-2011. Public Health Rep. 2016, 131, 839-843. [CrossRef]

56. Khalil, L.; McNeil, R.B.; Sims, K.J.; Felder, K.; Hauser, E.R.; Goldstein, K.M.; Voils, C.; Klimas, N.G.; Brophy, M.T.; Thomas, C.M.; et al. The Gulf War era cohort and biorepository: A longitudinal research resource of veterans of the 1990-1991 Gulf War era. Am. J. Epidemiol. 2018, 187, 2279-2291. [CrossRef] [PubMed]

57. Hunter-Zinck, H.; Shi, Y.; Li, M.; Gorman, B.R.; Ji, S.-G.; Sun, N.; Webster, T.; Liem, A.; Hieh, P.; Devineni, P.; et al. Measuring genetic variation in the multi-ethnic Million Veteran Program (MVP). bioRxiv 2020. [CrossRef]

58. Moore, R.; BIOS Consortium; Casale, F.P.; Bonder, M.J.; Horta, D.; Franke, L.; Barroso, I.; Stegle, O. A linear mixed-model approach to study multivariate gene-environment interactions. Nat. Genet. 2019, 51, 180-186. [CrossRef]

59. Das, S.; Forer, L.; Schöenherr, S.; Sidore, C.; Locke, A.E.; Kwong, A.; Vrieze, S.I.; Chew, E.Y.; Levy, S.; McGue, M.; et al. Next-generation genotype imputation service and methods. Nat. Genet. 2016, 48, 1284-1287. [CrossRef]

60. Genomes Project Consortium; Auton, A.; Brooks, L.D.; Durbin, R.M.; Garrison, E.P.; Kang, H.M.; Korbel, J.O.; Marchini, J.L.; McCarthy, S.; McVean, G.A.; et al. A global reference for human genetic variation. Nature 2015, 526, 68-74.

61. Fang, H.; Hui, Q.; Lynch, J.; Honerlaw, J.; Assimes, T.L.; Huang, J.; Vujkovic, M.; Damrauer, S.M.; Pyarajan, S.; Gaziano, J.M.; et al. Harmonizing genetic ancestry and self-identified race/ethnicity in genome-wide association studies. Am. J. Hum. Genet. 2019, 105, 763-772. [CrossRef]

62. Chang, C.C.; Chow, C.C.; Tellier, L.C.A.M.; Vattikuti, S.; Purcell, S.M.; Lee, J.J. Second-generation PLINK: Rising to the challenge of larger and richer datasets. GigaScience 2015, 4, 7. [CrossRef] [PubMed]

63. Loh, P.-R.; Kichaev, G.; Gazal, S.; Schoech, A.P.; Price, A.L. Mixed-model association for biobank-scale datasets. Nat. Genet. 2018, 50, 906-908. [CrossRef] [PubMed]

64. Hebbring, S. Genomic and phenomic research in the 21st century. Trends Genet. 2019, 35, 29-41. [CrossRef]

65. Bycroft, C.; Freeman, C.; Petkova, D.; Band, G.; Elliott, L.T.; Sharp, K.; Motyer, A.; Vukcevic, D.; Delaneau, O.; O'Connell, J.; et al. The UK Biobank resource with deep phenotyping and genomic data. Nat. Cell Biol. 2018, 562, 203-209. [CrossRef]

66. FinnGen. Available online: https:/ / www.finngen.fi/en (accessed on 21 June 2021).

67. Bulik-Sullivan, B.K.; Loh, P.R.; Finucane, H.K.; Ripke, S.; Yang, J.; Schizophrenia Working Group of the Psychiatric Genomics Consortium; Patterson, N.; Daly, M.J.; Price, A.L.; Neale, B.M. LD Score regression distinguishes confounding from polygenicity in genome-wide association studies. Nat. Genet. 2015, 47, 291-295. [CrossRef] [PubMed]

68. Bulik-Sullivan, B.; Finucane, H.K.; Anttila, V.; Gusev, A.; Day, F.R.; Loh, P.-R.; Duncan, L.E.; Perry, J.R.; Patterson, N.; Robinson, E.B.; et al. An atlas of genetic correlations across human diseases and traits. Nat. Genet. 2015, 47, 1236-1241. [CrossRef] [PubMed] 
69. Finucane, H.K.; ReproGen Consortium; Bulik-Sullivan, B.; Gusev, A.; Trynka, G.; Reshef, Y.; Loh, P.-R.; Anttila, V.; Xu, H.; Zang, C.; et al. Partitioning heritability by functional annotation using genome-wide association summary statistics. Nat. Genet. 2015, 47, 1228-1235. [CrossRef] [PubMed]

70. Gamazon, E.R.; GTEx Consortium; Wheeler, H.E.; Shah, K.P.; Mozaffari, S.V.; Aquino-Michaels, K.; Carroll, R.J.; Eyler, A.E.; Denny, J.C.; Nicolae, D.L.; et al. A gene-based association method for mapping traits using reference transcriptome data. Nat. Genet. 2015, 47, 1091-1098. [CrossRef]

71. TEx Consortium. Genetic effects on gene expression across human tissues. Nature 2017, 550, 204-213. [CrossRef]

72. Grotzinger, A.D.; Rhemtulla, M.; De Vlaming, R.; Ritchie, S.J.; Mallard, T.T.; Hill, W.D.; Ip, H.F.; Marioni, R.E.; McIntosh, A.M.; Deary, I.J.; et al. Genomic structural equation modelling provides insights into the multivariate genetic architecture of complex traits. Nat. Hum. Behav. 2019, 3, 513-525. [CrossRef]

73. Burgess, S.; Scott, R.A.; Timpson, N.J.; Smith, G.D.; Thompson, S.G.; EPIC-InterAct Consortium. Using published data in Mendelian randomization: A blueprint for efficient identification of causal risk factors. Eur. J. Epidemiol. 2015, 30, 543-552. [CrossRef]

74. Burgess, S.; Daniel, R.M.; Butterworth, A.S.; Thompson, S.G.; The EPIC-InterAct Consortium. Network Mendelian randomization: Using genetic variants as instrumental variables to investigate mediation in causal pathways. Int. J. Epidemiol. 2015, 44, 484-495. [CrossRef]

75. Burgess, S.; Thompson, S.G. Multivariable Mendelian randomization: The use of pleiotropic genetic variants to estimate causal effects. Am. J. Epidemiol. 2015, 181, 251-260. [CrossRef]

76. Gaziano, L.; Giambartolomei, C.; Pereira, A.C.; Gaulton, A.; Posner, D.C.; Swanson, S.A.; Ho, Y.-L.; Iyengar, S.K.; Kosik, N.M.; Vujkovic, M.; et al. Actionable druggable genome-wide Mendelian randomization identifies repurposing opportunities for COVID-19. Nat. Med. 2021, 27, 668-676. [CrossRef] 